Philologica Canariensia 23 (2017), pp. 63-78 eISSN: 2386-8635

DOI: 10.20420/PhilCan.2017.149

Recibido: 16 de marzo de 2017; versión revisada aceptada: 3 de mayo de 2017

Publicado: 26 de junio de 2017

\title{
EL LÉXICO DE UN CULTO CENTROAMERICANO EN LOS INICIOS DEL SIGLO XIX: NOTAS SOBRE LA MEMORIA DEL ESTADO POLÍTICO Y ECLESIÁSTICO DE LA CAPITANÍA GENERAL DE GUATEMALA (1821), DE J. M. MÉNDEZ*
}

\author{
JosÉ LUIS RAMÍREZ LUENGO \\ Universidad Autónoma de Querétaro
}

\begin{abstract}
RESUMEN: Este trabajo pretende contribuir al conocimiento de la historia del español centroamericano por medio del estudio del vocabulario de la Memoria del estado político y eclesiástico de la Capitanía General de Guatemala, que publica en 1821 el salvadoreño José Mariano Méndez. De este modo, se comenzará por facilitar una visión general del léxico de la obra haciendo hincapié en cuestiones como la presencia de vocabulario de la administración o del discurso ilustrado, para pasar a analizar aquellas unidades que se pueden considerar centroamericanismos desde una perspectiva de uso y dinámica de este concepto, con el propósito final de subrayar el proceso de dialectalización de este nivel lingüístico que se puede descubrir ya en estos momentos.
\end{abstract}

PALABRAS CLAVE: historia del español de América, léxico, siglo XIX, América Central

The lexicon of an educated Centroamerican at the beginning of the nineteenth century: some notes on J. M. Méndez's Memoria del estado político y eclesiástico de la Capitanía General de Guatemala (1821)

\begin{abstract}
This article aims to contribute to the history of Central American Spanish by studying the lexicon included in Memoria del estado político y eclesiástico de la Capitanía General de Guatemala, published by the Salvadorean priest José Mariano Méndez in 1821. I will first provide a general overview of the lexicon, highlighting the presence of vocabulary related to administrative issues and the learned discourse of the nineteenth century. Then, I will analyze different words that can be considered Central Americanisms, in order to call attention to the process of dialectalization already taking place at that time.
\end{abstract}

KEYWORDS: history of Latin American Spanish, lexicon, $19^{\text {th }}$ century, Central America

\section{LA DESCONOCIDA HISTORIA DEL ESPAÑOL CENTROAMERICANO}

Constituye ya un comienzo casi tópico cuando se habla sobre el español centroamericano ${ }^{1}$ mencionar la falta de atención que los investigadores han prestado en general a estas variedades, tanto en su vertiente sincrónica como muy especialmente en lo que se refiere a su diacronía; de hecho, desde este último punto de vista la carencia de estudios es tan llamativa que, al señalar hace ya veinte años la ignorancia que existe sobre la historia lingüística de ciertas áreas del continente americano, Medina López $(1995,46)$ ejemplifica su aserto, precisamente, con el caso de América Central. Si bien es verdad que 
en los últimos años se han desarrollado ya algunos trabajos acerca de esta cuestión (entre otros, Nieto, 1995; Pérez Cordón y Ramírez Luengo, 2006; Quesada Pacheco, 2009; Ramírez Luengo, 2004-2005, 2010, 2012), lo cierto es que las palabras del profesor canario resultan todavía perfectamente actuales, pues es prácticamente todo lo que aún se ignora sobre el devenir diacrónico del español en la zona.

Ahora bien, se hace preciso mencionar que, dentro de este desconocimiento general, no todos los niveles del sistema presentan el mismo grado de abandono. ${ }^{2}$ En este sentido, mientras que algunos como el fónico o el morfosintáctico cuentan ya con cierta cantidad de investigaciones dedicadas a la descripción de sus principales características en diferentes etapas de la historia (entre otras, Quesada Pacheco, 1987, 2013; Ramírez Luengo, 2003, 2006, 2008; Taracena Arriola, 1985; Ulate Zúñiga, 1991), el léxico sigue constituyendo un campo prácticamente virgen, para el que solo es posible señalar como investigaciones monográficas el completo trabajo de Quesada Pacheco (1995) sobre Costa Rica y los parciales de Polo Cano (2005) y Hernández (2008) sobre los indigenismos del español guatemalteco en los siglos XVII y XVIII, así como notas más o menos puntuales en algunos de los estudios anteriormente mencionados (Nieto, 1995; Quesada Pacheco, 2009; Ramírez Luengo, 2004-2005, 2010). De este modo, se puede concluir que la situación trazada en estas líneas evidencia la manifiesta necesidad que existe de llevar a cabo nuevas investigaciones que -especialmente en el campo del léxico- aporten luz sobre la evolución del español hablado en esta región, y proporcionen así los datos que aún se precisan para ir completando la historia lingüística de esta zona del continente en particular y de América en general.

\section{El TEXTO ESTUdiAdO: LA MEMORIA DE J. M. MÉNDEZ}

En esta línea, el presente trabajo pretende contribuir al conocimiento de la diacronía del español de Centroamérica por medio de la descripción y el estudio del vocabulario que aparece en la Memoria del estado político y eclesiástico de la Capitanía General de Guatemala, publicado en 1821 en Madrid por el religioso salvadoreño José Mariano Méndez. Se busca con ello, por tanto, atender a dos aspectos poco considerados en la escasa bibliografía existente acerca de la historia de las variedades lingüísticas centroamericanas: por un lado, el nivel léxico, que -según se ha indicado más arriba- cuenta por el momento con acercamientos muy parciales e insuficientes; por otro, el siglo XIX, sincronía prácticamente olvidada en los estudios lingüísticos sobre la región.

Por lo que se refiere al autor del texto, conviene indicar que, de acuerdo con las informaciones que aporta Belaubre (2015), José Mariano Méndez nace en la salvadoreña ciudad de Santa Ana Grande en 1777 en el seno de una familia de la élite regional, a juzgar por el cargo militar de su padre y por su condición de terratenientes. Orientado a la carrera eclesiástica, ingresa en el seminario conciliar de la capital guatemalteca en 1794, y en 1803 es ya no solo vicerrector del Seminario Tridentino, sino también persona de confianza del arzobispo, quien le encarga "hacer la visita pastoral de la parroquia de Chalchuapa, organizar el archivo del Provisorato, y constituir un cedulario y un índice”, posición que se reforzará posteriormente al alcanzar el "prestigioso puesto de cura de la parroquia de El Sagrario, en la capital del Reino" (Belaubre, 2015); por otro lado, en 1805 se gradúa de abogado y culmina algo después, en 1811, sus estudios con un doctorado en Sagrados Cánones, momento en el que es comisionado a la Intendencia de San Salvador con la misión 
de impedir que este territorio se una a los movimientos independentistas. Tras esta misión, en 1815 pasa a España como diputado por Sonsonate en las Cortes Generales, y en este país reside por lo menos hasta 1824 , cuando regresa a Guatemala. Una vez de vuelta, las circunstancias políticas resultan adversas para el clérigo santaneco, pues -en el marco de la guerra civil que afecta a la región en esos años- el gobierno conservador de Mariano Aycinena juzga muy negativamente sus actividades anteriores, de manera que es obligado a recluirse en "el convento de la Recolección" de Guatemala, donde vivirá aún veinte años más para fallecer, en 1850, en la ciudad de Escuintla.

A la vista, pues, de toda la información facilitada hasta el momento, es posible describir al Presbítero Méndez, si no como un ilustrado, sí por lo menos como un claro representante de la minoría cultivada que forma parte de los estratos más elevados de la sociedad centroamericana en las postrimerías del dominio español. Es precisamente desde esta perspectiva desde la que se debe interpretar la Memoria del estado político y eclesiástico de la Capitanía General de Guatemala que, según se ha dicho ya, publica en Madrid en $1821,{ }^{3}$ así como la finalidad que pretende con esta obra y los temas y contenidos que aparecen en ella.

Por lo que se refiere al texto en sí, cabe indicar que se trata de un impreso muy breve, de apenas 30 páginas, en el que se presenta una descripción -física, económica, demográfica y administrativa - de la Capitanía General de Guatemala, así como una posible reorganización de estos territorios "que debía desembocar en la creación de ocho provincias" (Belaubre, 2015) en aras de su más efectivo y racional aprovechamiento económico. ${ }^{4}$ Este propósito reformista -presente también en otros autores americanos de la época, que comparten con el religioso salvadoreño unas preocupaciones comunesexplica la aparición en el texto de cuestiones como, por ejemplo, la situación de pobreza y explotación de la población nativa (pp. 25, 26), el comercio y las formas de desarrollarlo (pp. 11, 12, 15, 17), el interés por el fomento de la educación (pp. 19, 21, 22, 30) o las quejas por el desplazamiento de los criollos ante los peninsulares (pp. 20, 21), a las que se suman, además, asuntos específicamente centroamericanos, entre los que cabe señalar la crítica por el abandono que sufre la región y la corrupción institucional (pp. 5, 17, 25, 26), algunas notas sobre la situación lingüística de las distintas provincias (pp. 3, 9, 12, 21) o el plan de crear un canal interoceánico a través del lago de Nicaragua (p. 8).

Por lo tanto, se puede definir el corpus que se va a tratar en este estudio como la obra de un centroamericano perteneciente a los círculos socioeconómicamente más elevados de su sociedad que, desde el punto de vista textual, se inserta en una tipología -la memoria administrativa reformista- que resulta muy frecuente en esta época y que se caracteriza por ofrecer una descripción detallada de la realidad que rodea a su autor. Así las cosas, es precisamente la suma de ambas características, el origen centroamericano de este ${ }^{5}$ y su intención de ofrecer una descripción realista de la región, lo que determina la importancia que presenta esta memoria para el estudio histórico del léxico de la América Central del siglo XIX, al combinarse en él el ámbito intelectual y el vocabulario que le es propio con otros más cercanos a la cotidianeidad y, por ello, más susceptibles de ofrecer voces diatópicamente marcadas.

De este modo, la intención de estas páginas no es otra que facilitar una visión general del léxico de la obra haciendo hincapié en sus características geográfica o cronológicamente más identificadoras. Así, tras señalar la presencia en el texto del vocabulario de la administración o del discurso ilustrado decimonónico, se pasará a analizar todas aquellas 
unidades que se pueden considerar centroamericanismos desde una perspectiva de uso y dinámica de este concepto (Ramírez Luengo, 2015), con el propósito final de subrayar el proceso de dialectalización de este nivel lingüístico que se puede descubrir ya en estos momentos y su reflejo en el corpus aquí considerado.

\section{El LÉXICO CENTROAMERICANO DECIMONÓNICO EN LA MEMORIA DE J. M. MÉNDEZ}

No cabe duda de que uno de los aspectos que más llama la atención en una primera lectura de la Memoria de José Mariano Méndez es la convivencia en el mismo escrito de léxico perteneciente a esferas nocionales muy diferentes, esto es, el empleo de voces muy apegadas a la realidad más cercana junto con otras que se asocian a ámbitos mucho más intelectuales, algo que no resulta en realidad sorprendente si se tienen en cuenta circunstancias ya mencionadas como el nivel social del presbítero salvadoreño, la tipología textual a la que pertenece su texto, la finalidad que persigue con él y los temas que se tratan en sus páginas. Es necesario señalar en primer lugar, por tanto, la presencia de una serie de vocablos que pertenecen al léxico intelectual, sea este el del discurso propiamente ilustrado (a manera de ejemplo, felicidad, utilidad, instrucción o libertad, p. 17) o el de la política de su tiempo -entre otros, (madre) patria, nación (española) o legislatura (pp. 17, 18)- y que, lejos de ser privativos de este autor, aparecen también en obras dieciochescas y decimonónicas de temática cercana escritas a ambos lados del Atlántico, como bien han estudiado, entre otros, Álvarez de Miranda (1992), García Godoy (1999) o Hildebrandt (1961).

También en relación con este ámbito intelectual, no cabe duda de que un texto que pretende proponer una radical reforma de la división administrativa de la Audiencia de Guatemala necesariamente tiene que incorporar voces pertenecientes a la esfera de la administración civil y religiosa, de lo que constituyen excelentes ejemplos términos como alcaldía mayor, corregimiento, intendencia (p. 4), mesada, junta diocesana o prebendado (p. 29). Con todo, es probable que dentro de esta temática los vocablos más interesantes no sean los que se acaban de señalar, de carácter más o menos general por su presencia en toda la burocracia colonial hispánica, sino aquellos más restringidos que parecen ser característicos del español empleado en América en estos momentos. A manera de ejemplo, cabe mencionar doctrina (pp. 6, 20, 26), reducción (pp. 6, 21) y ejido (p. 20) que, frente a sus significados españoles, en la obra presentan los de 'distrito eclesiástico servido por un sacerdote expresamente nombrado para adoctrinar a la población indígena', 'pueblo de indígenas convertidos al cristianismo' (DRAE, 2014, s.v. doctrina, reducción) y 'forma de propiedad de la tierra que consiste en la asignación estatal de un terreno a un grupo de campesinos para su explotación colectiva' (DAMER: s.v. ejido) respectivamente, ${ }^{6}$ así como cofradía (pp. 20, 21), que en la memoria de Méndez mantiene el valor de 'vecindario, unión de personas o pueblos congregados entre sí para participar de ciertos privilegios', ${ }^{7}$ arcaico ya para Autoridades (Real Academia Española, 1979, s.v. cofradría) y desconocido en España en la primera mitad del siglo XIX según los datos de CORDE, ${ }^{8}$ en lo que parece constituir una nueva muestra del conocido conservadurismo que, desde el punto de vista léxico, presentan frecuentemente las variedades americanas del español.

Por otro lado, es asimismo posible mencionar aquí otro elemento como valle (pp. 6, 8, 11, 20, 21), que es definido por el mismo Méndez como "población que no tiene iglesia ni formalidades de pueblo" (p. 6); coincide su significado, por tanto, con el que el DAMER 
(s.v. valle) registra para esta voz en Paraguay, y que Granda (1994) considera un septentrionalismo peninsular en el español americano. ${ }^{9}$ Del mismo modo, es también destacable el término curato (pp. 7, 8, 10, 12, 14, 22, 28, 29, etc.) 'parroquia, territorio bajo la jurisdicción espiritual de un cura' (DRAE, 2014, s.v. curato), en este caso no tanto por su desconocimiento en la España de las primeras décadas del siglo XIX como por su mayor utilización en las tierras del Nuevo Mundo, según demuestra claramente el corpus diacrónico de la Real Academia (CORDE). ${ }^{10}$

Es posible, por tanto, registrar en el texto una serie de vocablos que, bien por su significado o bien por su frecuencia de uso en la época, se pueden calificar como americanismos, entendiendo este concepto a partir de la definición de Company (2007, 28-9) como "el conjunto de voces, formas o construcciones que son caracterizadoras del habla urbana, popular o culta, o ambas, de América y cuyo uso muy frecuente y cotidiano distancia la variedad americana respecto del español peninsular". Naturalmente, si esto es así en un ámbito en principio tan poco propicio para los términos diatópicamente marcados como es el administrativo, no puede sorprender que resulten aún más abundantes en aquellas esferas conceptuales que hacen referencia a realidades más cercanas como, por ejemplo, los productos de la región, los enseres y utensilios o la geografía y el clima. De este modo, a los términos ya mencionados en los párrafos anteriores se puede sumar un conjunto de 22 vocablos que encajan con la descripción que se ha facilitado del americanismo, a saber: achiote, añil, bálsamo, bejuco, cacao, canoa, cerro, estero, fierro, frijol, hacienda, hamaca, ingenio, invierno, jarcia, ladino, mineral, pajallú, pellón, pita, prolijo y tenance.

Por supuesto, salta a la vista que no todos estos elementos cumplen exactamente de la misma manera la definición expuesta más arriba, de lo que se deduce que dentro de este concepto existen diversos subtipos, que Company (2010, xvii) determina desde el uso y cifra en tres diferentes, en concreto americanismos puros, semánticos y de frecuencia. Como es habitual en estos casos, la Memoria del presbítero santaneco ofrece muestras de todos ellos, si bien en porcentajes relativamente dispares, según se expone en la tabla 1:

\begin{tabular}{|c|c|c|}
\hline AMERICANISMO & CASOS & TÉRMINOS \\
\hline Puro & $5\left(17^{\prime} 85 \%\right)$ & achiote, ${ }^{11}$ bejuco, pajullú, pellón, tenance \\
\hline Semántico & $15\left(533^{\prime} 57 \%\right)$ & $\begin{array}{c}\text { bálsamo, cerro, cofradía, doctrina, ejido, hacienda, } \\
\text { hamaca, ingenio, invierno, }{ }^{12} \text { jarcia, ladino, mineral, } \\
\text { prolijo, reducción, valle }\end{array}$ \\
\hline Frecuencia & $8\left(28^{\prime} 57 \%\right)$ & $\begin{array}{c}\text { añil, cacao, canoa, curato, estero, fierro, } \\
\text { frijol, pita }\end{array}$ \\
\hline TOTAL & $28(100 \%)$ & \\
\hline
\end{tabular}

Tabla 1. Distribución de los americanismos del texto por tipos

A la luz, pues, de estos primeros datos, se hacen evidentes dos cuestiones de cierto interés para la mejor comprensión del léxico diatópicamente marcado que aparece en la obra de Méndez: por un lado, que en los tres subtipos de americanismos aparecen voces de origen indígena -especialmente en el caso de los puros, donde son mayoritarias, pero también en los semánticos (hamaca) y los de frecuencia (cacao, canoa, pita)- y otras pertenecientes al fondo patrimonial hispánico, algo que demuestra lo oportuno de definir este concepto no tanto por el origen etimológico de los vocablos considerados como por su uso en un momento determinado (Company, 2007, 28-9; Ramírez Luengo, en prensa); por 
otro, que son los denominados americanismos semánticos, con algo más del 50\% del total, los más abundantes en el texto. Ello puede responder a cuestiones muy variadas, que van desde la temática tratada en la obra hasta el hecho de que esta se publique en España, lo que probablemente obliga a Méndez a sustituir en la medida de lo posible los americanismos puros, es decir, aquellos elementos que pueden resultar de más difícil comprensión para un público de este origen dialectal.

Por lo que se refiere a los americanismos puros, quizá sean especialmente destacables por su escasa atestiguación histórica los términos pajullú (p. 22) y tenance (p. 25). En el primer caso se trata de una voz de origen maya que se refiere al sistema de organización social que rige entre los indígenas no adaptados al régimen colonial, y cuya primera datación -a falta de noticias en CORDE, CORDIAM o LEXHISP - es la cita de Juarros $(1810,122)$ de que "los indios en tiempo de su gentilidad tenían poblaciones mas estas eran como algunas que todavía existen al presente y llaman Pajuyues". ${ }^{13}$ En cuanto a tenance -de nuevo, sin atestiguaciones en los corpus ya mencionados (CORDE, CORDIAM, LEXHISP)-, es probable que no sea sino la variante salvadoreña del nahuatlismo tenanche, que Morínigo (1998, s.v. tenanche) localiza en México con el significado de "mujer que se ocupa del aseo de los templos e imágenes religiosas" y cuyo significado resulta perfectamente válido para el contexto en que aparece en el corpus ("por lo que mira al servicio de cofradías ... se hace elección cada año de mayordomos, mayores y tenances", p. 25).14 Asimismo, cabe destacar también dentro de esta categoría el caso de pellón (p. 11), que si bien en principio se podría entender como americanismo semántico -por su significado español de 'vestido talar antiguo' contrapuesto al americano de 'pelleja curtida que se usa sobre la silla de montar' (DRAE, 2014, s.v. pellón) ${ }^{15}$-, en este caso se ha optado por su valoración como puro a la luz de los datos de CORDE, que solo ofrece ejemplos americanos para los siglos XVIII y XIX, periodo en que se enclava el texto estudiado. ${ }^{16}$

En cuanto a los americanismos semánticos, se ha indicado ya que son con mucho los más frecuentes en el texto. ${ }^{17}$ Se descubren en ámbitos tan variados como la administración -los ya mencionados cofradía, doctrina o reducción (pp. 21; 6, 20, 26; 6, 21)-, la geografía y el clima (cerro 'monte, pico más alto que el cerro español', Richard, 1997, s.v. cerro; invierno 'temporada de lluvias', DAMER, 2010, s.v. invierno, pp. 21; 17) y los espacios de producción económica (hacienda 'finca agrícola', DRAE, 2014, s.v. hacienda; ${ }^{18}$ mineral 'lugar donde abunda algún mineral valioso', DAMER, 2010, s.v. mineral; ingenio 'planta donde se procesa el mineral', DAMER, 2010, s.v. ingenio, ${ }^{19}$ pp. 7, 8, 11; 3, 7, 9, 11; 11, 15), a lo que se suma incluso un adjetivo como prolijo, que, frente a su sentido español de 'largo, dilatado con exceso', en el texto presenta el americano de 'cuidadoso o esmerado' (DRAE, 2014, s.v. prolijo), ${ }^{20}$ tal y como parece poner de manifiesto el siguiente ejemplo: "ha sacrificado tiempo y trabajo prolijo de muchos años para registrar archivos" (p. 4).

Ahora bien, no cabe duda de que los vocablos más interesantes de este grupo son aquellos que resultan diatópicamente más circunscritos y se relacionan específicamente con el área centroamericana. En este sentido, cabe mencionar, por ejemplo, bálsamo (pp. 5, 11), que tanto el DRAE (2014, s.v. bálsamo) como Morínigo (1998, s.v. bálsamo) consideran nombre genérico para gran variedad de árboles americanos, pero que el DAMER (2010, s.v. bálsamo) define como voz propia de Guatemala, Honduras, Nicaragua y El Salvador para el myroxylum balsamum, o ladino (p. 26), que -frente a su significación más general de 'mestizo o indio hablante de español' (Buesa y Enguita, 1992, 165; DMEX, 2010, s.v. ladino) - en el texto presenta el valor propiamente centroamericano de 'mestizo' 
(DAMER, 2010, s.v. ladino), sin ninguna referencia a sus hábitos lingüísticos. ${ }^{21}$ Junto a los anteriores, también pertenecen a esta categoría los vocablos jarcia (pp. 11, 12, 14), marinerismo adaptado que ha modificado su primitivo valor de 'aparejos y cabos de un buque' (DCECH, 1980-1991, s.v. jarcia) para pasar a significar 'conjunto de objetos de fibra vegetal' en todas las repúblicas del Istmo y México (DAMER, 2010, s.v. jarcia; DMEX, 2010, s.v.jarcia), y hamaca, que, según se desprende de su contexto de aparición ("crecidos ríos, que a veces no dan bados y se pasan por amacas de vejucos”, p. 21), presenta en la memoria la significación -desconocida en el resto del continente (CORDIAM, LEXHISP)que Quesada Pacheco (1995, s.v. hamaca) señala en la Costa Rica colonial, esto es, 'puente colgante hecho a la manera de hamacas'.

Por su parte, los americanismos de frecuencia se reducen únicamente a ocho vocablos, y todos ellos se caracterizan por presentar durante los siglos XVIII y XIX un empleo mucho más abundante en los textos americanos, según demuestran fehacientemente los datos de CORDE. Naturalmente, tal circunstancia es lo esperable en el caso de unidades referidas a productos y realidades americanas como curato, ya mencionado más arriba, cacao, canoa, pita (pp. 5, 6, 9, 11, 12, 14; 21; 11) y muy especialmente añil (pp. 5, 8, 9, 10, 11, 12), de fundamental importancia en la economía regional hasta bien entrado el siglo XIX (Pérez Brignoli, 2000, 77), ${ }^{22}$ pero quizá no lo sea tanto en lo que respecta a otras voces como el marinerismo estero 'terreno bajo pantanoso' (DRAE, 2014, s.v. estero; Buesa y Enguita, 1992, 184) (p. 8), que en el Nuevo Mundo “conserva vida más lozana” (DCECH, 1980-1991, s.v. estero $)^{23}$ y que Frago $(2010,189)$ considera meridionalismo general en América ya antes de la Independencia, fierro (pp. 3, 11) -con 2'12 ejemplos españoles por millón de palabras frente a 20'06 americanos ${ }^{24}$ - ofrijol (pp. 6, 8, 9, 10, 11, 12, 14), que es interpretado como término propiamente americano por el presbítero salvadoreño ${ }^{25}$ y que, efectivamente, resulta a este lado del Atlántico mucho más frecuente que en la metrópoli, con 7'54 casos frente a un casi simbólico o'66. Es posible descubrir en la obra, por tanto, una serie de unidades que, se refieran a realidades propias del continente o no, en todo caso evidencian ciertas preferencias léxicas que, dentro del vocabulario español, manifiestan las diversas variedades del Nuevo Mundo, en un claro proceso de selección normativa que también contribuye -y no poco- a la dialectalización de este nivel lingüístico.

Desde otro punto de vista, y aunque el corpus resulta demasiado breve como para extraer de él conclusiones generales, no está de más analizar la configuración léxica que se refleja en sus páginas. Como se ha señalado en trabajos previos (Ramírez Luengo, en prensa), este concepto se define como la "preferencia que muestra una determinada variedad por una de las posibles estrategias (modificación/incorporación) que se emplean a la hora de dialectalizar el léxico", algo que, en este caso específico, se concreta en los datos que se exponen en la tabla 2.

\begin{tabular}{|c|c|c|}
\hline ESTRATEGIA & CASOS & TÉRMINOS \\
\hline Incorporación & $10(40 \%)$ & $\begin{array}{c}\text { achiote, batata, bejuco, cacao, canoa, hamaca, maíz, } \\
\text { pajullú, pita, tenance }\end{array}$ \\
\hline Modificación & $15(60 \%)$ & $\begin{array}{c}\text { bálsamo, cerro, cofradía, doctrina, ejido, hacienda, ingenio, } \\
\text { invierno, jarcia, ladino, mineral, pellón, prolijo, } \\
\text { reducción, valle }\end{array}$ \\
\hline TOTAL & $25(100 \%)$ & \\
\hline
\end{tabular}

Tabla 2. Configuración léxica de la Memoria de J. M. Méndez

Philologica Canariensia 23 (2017), 63-78 eISSN: 2386-8635 
De acuerdo, pues, con estos primeros datos, salta a la vista que -como era de esperarambas estrategias hacen acto de aparición en el texto, si bien con un predominio más o menos claro, de 20 puntos porcentuales, de la modificación sobre la incorporación. Si ello en general se explica por determinados factores sociohistóricos que conforman la composición de las diversas sociedades coloniales, ${ }^{26}$ en este caso concreto probablemente responda a cuestiones de índole textual, tales como los receptores de la obra -españoles no familiarizados con los indigenismos, para los cuales estos términos pueden suponer, por tanto, una dificultad en la comprensión- o incluso la propia temática, que -frente a lo que ocurre, por ejemplo, en escritos acerca de la flora o fauna regional- no favorece la presencia mayoritaria de voces de origen autóctono. ${ }^{27}$

En esta misma línea, resulta también interesante describir los campos semánticos a los que se incorporan las voces que reflejan ambas estrategias de configuración léxica, por cuanto ofrecen una idea clara acerca de las realidades que se ven afectadas en forma preferente por estos procesos. De este modo, la clasificación de estos vocablos a partir de las categorías que establecen Quirós García y Ramírez Luengo $(2015,197)$ es la que se presenta a continuación (tabla 3):

\begin{tabular}{|c|c|c|}
\hline CAMPO SEMÁNTICO & INCORPORACIÓN & MODIFICACIÓN \\
\hline Organización social & pajullú, tenance & $\begin{array}{c}\text { cofradía, doctrina, } \text { ejido, } \\
\text { ladino, reducción, valle }\end{array}$ \\
\hline Industria / construcción & & hacienda, ingenio, mineral \\
\hline Enseres / utensilios & bejuco, canoa, hamaca, pita & jarcia, pellón \\
\hline Agricultura & achiote, batata, cacao, maíz & bálsamo \\
\hline Clima / geografía & & cerro, invierno \\
\hline Otros & 10 & prolijo \\
\hline TOTAL & & 15 \\
\hline
\end{tabular}

Tabla 3. Distribución de las voces de la configuración léxica por campos semánticos

$\mathrm{Al}$ igual que se indicó anteriormente, la escasez de elementos léxicos que ofrece el corpus impide hacer generalizaciones de ningún tipo. En todo caso, parece importante señalar -en consonancia con lo indicado en diversos estudios (Mejías, 1980, 19; Ramírez Luengo, 2007, 79-80) - la clara preponderancia del indigenismo en aquellos campos semánticos más cercanos a la materialidad americana como son los enseres y los productos agrícolas, mientras que la modificación aparece repartida en ámbitos nocionales más variados, entre los que destaca la industria y la organización social, algo que probablemente se deba relacionar, una vez más, con las propias características, tipológicas y temáticas, de la obra que se está analizando.

En cuanto a los indigenismos en sí, cabe indicar que -con la excepción de los ya analizados pajullú y tenance- en general su presencia en el texto no resulta en modo alguno sorprendente, ni en lo que tiene que ver con su cronología ni en lo que se refiere a sus orígenes etimológicos. En el primero de los casos, porque todos ellos se registran ya desde los primeros tiempos de presencia española en el Nuevo Mundo; ${ }^{28}$ en lo que toca a la segunda cuestión, porque todos ellos pertenecen o bien a los idiomas presentes en la región -como el náhuatl (achiote, cacao, tenance) y el maya (pajullú) - o bien a las lenguas antillanas (batata, bejuco, canoa, hamaca, maíz, pita), es decir, a las lenguas amerindias 
que de manera más frecuente aportan unidades léxicas al español centroamericano (Ramírez Luengo, 2007, 76-78).29

Por otro lado, el estudio de los americanismos en su sentido más amplio no agota todas las posibilidades que ofrece la obra de Méndez para el mejor conocimiento de la situación léxica que muestra América Central en los primeros años del siglo XIX; muy por el contrario, todavía es necesario mencionar la presencia de otros vocablos en sus páginas que, desde diversos puntos de vista, resultan de evidente interés, y cuyo estudio futuro puede abrir nuevas líneas de trabajo que será preciso explorar en posteriores estudios. A este respecto, cabe señalar en primer lugar la aparición de una voz que por el momento parece constituir un auténtico hápax léxico, a saber, guatacón, cuya aparición en un binomio léxico junto al término molendera 'persona que muele o lleva que moler a los molinos' (DRAE, 2014, s.v. molendero) (“dos mujeres llamadas guatazones o molenderas"; p. 26), parece descubrir ya la significación del término, pero sigue sin aportar noticias acerca de su origen, que quizá se encuentre en el nahuatlismo guate, empleado en Honduras, Nicaragua y Costa Rica para el 'maíz sembrado de manera muy tupida que se aprovecha solo como forraje' (DAMER, 2010, s.v. guate); ${ }^{30}$ por otro lado, se registra también el vocablo palleta en el compuesto polvo de palleta ("en ella está situado el célebre río de Guayape, de donde se saca mezclado con sus arenas el oro en polvo de palleta”, p. 9), que constituye un tecnicismo de la química definido como 'laminita muy delgada de oro' (Domínguez, 1853, s.v. palleta) y cuya primera datación por el momento parece ser, precisamente, este ejemplo que ofrece la obra de Méndez.

Por último, no se puede obviar la presencia en la Memoria del españolismo patata ‘tubérculo' (DRAE, 2014, s.v. patata) (pp. 12, 14), cuya aparición en la obra merece también una reflexión: en efecto, abandonada la idea de que se trate de una mera errata por batata -término al que acompaña en una enumeración (p. 12)-, es necesario preguntarse si estos ejemplos constituyen una muestra de su utilización en la América de la época o más bien responden a otras circunstancias que tienen que ver con las propias características del texto. A este respecto, los datos americanos de CORDE, CORDIAM y LEXHISP ofrecen casos puntuales y puramente anecdóticos de este vocablo en América durante los siglos XVIII y XIX, ${ }^{11}$ de manera que es probable que su utilización por parte del presbítero Méndez se deba entender como una concesión de este para favorecer la comprensión de la obra por parte del público español al que va dirigida, o incluso como un cambio léxico efectuado por los mismos editores madrileños, hipótesis ambas de difícil comprobación pero que en todo caso descartan la idea de que tales ejemplos sean una muestra de la vitalidad de esta voz en el español centroamericano de las primeras décadas del siglo XIX. ${ }^{22}$

\section{CONCLUYENDO: ALGUNOS DATOS SOBRE LA HISTORIA LÉXICA DE AMÉRICA CENTRAL}

A la luz, pues, de lo indicado hasta el momento, se hace ahora del todo necesario recopilar una serie de cuestiones acerca del vocabulario empleado por J. M. Méndez en su obra que resultan de notable interés para obtener una visión más completa del léxico centroamericano de la primera parte del siglo XIX. Tales cuestiones permitirán, además, alcanzar un conocimiento más profundo del devenir diacrónico de este nivel lingüístico en el español de América, así como de los procesos históricos que, con el paso del tiempo, han dado lugar a la situación que ofrecen actualmente estas variedades de la lengua. 
A este respecto, quizá el aspecto más interesante que se extrae del estudio sea la presencia en el texto de elementos que ya en estos momentos se pueden considerar centroamericanismos, por constituir vocablos que de alguna manera resultan identificadores de las hablas propias de la región. En efecto, términos como bálsamo, hamaca 'puente', jarcia, ladino 'mestizo' o tenance demuestran bien a las claras que para la época en que se redacta esta obra se ha producido ya cierta selección normativa léxica -en forma de imposición de diversos americanismos, puros, semánticos y de frecuencia (Company, 2010, xvii)- que da como resultado la dialectalización de esta parte del sistema lingüístico, en consonancia con lo que ya se había señalado para otras áreas del continente en estos mismos momentos (Ramírez Luengo, 2011, 85-86). Cabe mencionar, además, que tales voces diatópicamente marcadas se descubren en campos semánticos favorecedores de este fenómeno -como la agricultura o los enseres y utensilios-, pero también en otros que a priori podrían parecer más reacios como, por ejemplo, la administración o la organización social, lo que demuestra que el proceso de transformación léxica que implica el trasplante del español a América constituye una auténtica reorganización de este nivel lingüístico en todos sus ámbitos, y no solo la incorporación de unidades aisladas a ciertas partes del mismo.

Por otro lado, vale la pena mencionar también el claro predominio en el corpus de los denominados americanismos semánticos y, en estrecha relación con ello, de la estrategia de modificación sobre la de incorporación, algo que trae como consecuencia una muy escasa presencia de elementos de origen indígena en sus páginas. Por supuesto, tal carencia de indigenismos parece responder en esta ocasión no tanto a los factores sociohistóricos que a veces se han invocado para justificar las diversas configuraciones léxicas regionales como a diversas cuestiones de índole textual que se relacionan con la tipología de la obra, sus receptores o incluso su propia temática, aspectos todos que adquieren una relevancia fundamental a la hora de interpretar los datos de un estudio como el presente y que será necesario tener en cuenta en aproximaciones futuras a esta materia que hagan uso de una metodología semejante a la aquí empleada. Finalmente, es preciso recordar también que el interés de la Memoria de Méndez para el mejor conocimiento del léxico histórico centroamericano no se agota en los americanismos, y a este respecto es destacable la presencia en sus páginas de un auténtico hápax y una primera datación, guatazón y palleta respectivamente, así como del españolismo patata, cuyo origen, significado y ámbito de uso -en el caso de este último- será necesario estudiar en posteriores trabajos que cuenten con corpus documentales más extensos.

En todo caso, y más allá de estas conclusiones provisionales, hay algo que resulta evidente a partir de esta primera aproximación a la obra del presbítero santaneco, y es que, tanto por la falta de noticias que existe respecto a esta cuestión como por los ricos resultados que se pueden obtener de su análisis, se hace absolutamente necesario seguir investigando el vocabulario de los textos que se redactan en la Centroamérica decimonónica. Únicamente de esta manera será posible comprender en un futuro cercano tanto la realidad léxica de América Central en otros momentos de su historia como muy especialmente los procesos -aún desconocidos- que, desde este punto de vista, dotan de su indudable personalidad a las variedades lingüísticas que se emplean hoy en esta área del mundo hispánico. 


\section{NOTAS}

* Este estudio forma parte del proyecto Léxico Histórico del Español Centroamericano (16501819), financiado por la Secretaría de Educación Pública (México) en el marco del programa PRODEP - Incorporación de nuevos PTCs para el periodo 2016-2017.

1 Conviene aclarar que en este trabajo se entiende Centroamérica desde un punto de vista histórico, es decir, como aquellos territorios que durante la época colonial formaron parte del virreinato de la Nueva España y, más específicamente, de la Audiencia de Guatemala (las actuales repúblicas de Guatemala, El Salvador, Honduras, Nicaragua y Costa Rica). Queda fuera de esta lista, por tanto, Panamá, que si bien se integra en la región desde el punto de vista geográfico, históricamente siempre estuvo más relacionado con otras áreas, como la actual Colombia y el Caribe en general.

2 Tampoco todos los países del Istmo: la situación de Costa Rica -país para el que existen ya trabajos amplios y de importancia (entre otros, Quesada Pacheco, 1995, 2009)- es notablemente mejor, por ejemplo, que la que se descubre en el caso de El Salvador o Nicaragua, zonas en las que la falta de análisis es casi total (Ramírez Luengo, 2010, 2012).

3 Según se indica en el pie de la misma obra, en la Imprenta de D. Fermín de Villalpando. Es de esta edición de donde se toman todos los ejemplos citados en el trabajo.

4 Por supuesto, las motivaciones del clérigo salvadoreño no son del todo altruistas, ya que, como bien señala Belaubre (2015), su propuesta tiene una doble ventaja para él: por un lado, al proponer la creación de una provincia con capital en su Santa Ana natal contribuye a "la concentración del poder, en máximo grado, en las manos de su familia de origen"; por otro, favorece al mismo tiempo "los intereses de las familias de poder de la capital del Reino, ya que El Salvador iba a ser de hecho dividido en dos provincias equilibradas y con menos capacidad de competir políticamente con la región de la Ciudad de Guatemala".

5 Pese a su nacimiento en El Salvador, el hecho de que José Mariano Méndez desarrolle gran parte de su vida en la actual Guatemala determina que muy posiblemente experimente procesos de acomodación y nivelación dialectal (Penny, 2004, 74-77) que modifiquen parcialmente su variedad materna de español; precisamente por esto se opta en estas líneas por destacar su naturaleza centroamericana y no tanto salvadoreña, algo que, por otro lado, se ve favorecido por la posibilidad -quizá más discutible en el nivel léxico- de considerar a toda América Central como una única área dialectal, según defienden diferentes autores (Quesada Pacheco, 1996, 113-4).

6 De forma más discutible, quizá también se pudiera incorporar a este grupo de términos administrativos modificados semánticamente cabecera, que el religioso centroamericano se ocupa de definir como "pueblo de la residencia del párroco" (p. 21); con todo, su evidente cercanía al valor general de 'capital o población principal de un territorio o distrito' (DRAE, 2014, s.v. cabecera) ha determinado que no se considere como tal.

$7 \mathrm{Al}$ menos eso parece deducirse de su aparición junto a otros vocablos como curato, reducción, iglesia y parroquia, todos ellos núcleos de población: "tiene 35 curatos, una reducción de infieles en 145 iglesias, 231 valles y 336 cofradías” (p. 21).

8 Tampoco parece ser muy utilizado con tal significación en América, pues CORDIAM ofrece un único ejemplo -en Campeche, en 1804- con este valor.

9 A este respecto, quizá lo más interesante de esta atestiguación inequívoca de valle en la memoria salvadoreña como 'región o pueblo de un país, sea o no en zona montañosa' (DAMER, 2010, s.v. valle) sea la demostración de que tal valor no constituye un uso exclusivo del español paraguayo -al menos, en la primera mitad del siglo XIX-, lo que permite, por tanto, no solo precisar su ámbito histórico de uso en América, sino también corroborar el aserto de Frago $(2010,198)$ de que "a veces incluso el aparato documental amplía la geografía léxica de los diccionarios americanistas". 
10 En concreto, los datos para los siglos XVIII y XIX son los siguientes: 244 ejemplos españoles (5’56 apariciones por millón de palabras) frente a 603 americanos (48’39 apariciones por millón de palabras), es decir, una frecuencia casi diez veces superior en el Nuevo Mundo, donde, además, aparece repartido por todo el continente, según demuestra CORDIAM.

11 La consideración de achiote como americanismo puro resulta discutible, habida cuenta de su presencia histórica en el español canario (Corrales Zumbado y Corbella, 2010: s.v. achiote); con todo, lo restringido de su uso y su aparición específica en esta región parecen favorecer su clasificación dentro de esta categoría para los fines contrastivos de este estudio.

12 Al igual que en el caso de achiote, el carácter de americanismo de invierno 'temporada de lluvias' resulta discutible en la actualidad, habida cuenta de que este valor aparece también a día de hoy en el español de las islas Canarias (Corrales Zumbado y Corbella, 2010: s.v. invierno). Cabe preguntarse, con todo, si este uso existe ya en el archipiélago en los primeros años del siglo XIX o constituye, como indican los autores citados, un préstamo -relativamente moderno- del español venezolano, cuestión que no es posible analizar en este momento.

13 El que el término aparezca en el texto en cursiva ("es de absoluta necesidad desterrar para evitar que vivan como bestias en las montañas desiertas que llaman pajullues") parece manifestar que se trata de un ocasionalismo, es decir, de voces "que no pertenecen al uso habitual de la lengua receptora, sino que se usan ocasionalmente en ella [...] con plena conciencia de su condición de extranjeras y sin voluntad de integrarlas" (Álvarez de Miranda, 2009, 144); esta idea se ve reforzada por el hecho de que en la obra de Juarros también aparezca con la misma marca tipográfica.

14 La diferencia entre la palatal africada y la alveolar no es ningún impedimento a la hora de relacionar ambas variantes, pues es más que sabido que la africada originaria del náhuatl (tenantzin, de acuerdo con Santamaría, 1959, s.v. tenanche) presenta ambas soluciones en su adaptación al español; por otro lado, tampoco resulta problemática la asociación del cargo a otros masculinos como "mayordomos y mayores", pues el mismo Santamaría (1959, s.v. tenanche) indica que "el nombre se ha hecho extensivo al vecino de cualquier sexo que asume tales deberes".

15 El DAMER (2010, s.v. pellón) aporta también una significación propiamente guatemalteca para este vocablo ('tejido grueso de lana que se utiliza generalmente para hacer alfombras'); desgraciadamente, la falta de concreción del fragmento en que se emplea ("traen vinos, aceite, pasas, peyones, Ropa de la China, cacao", p. 11) impide determinar con exactitud a qué se refiere Méndez en su obra.

16 En concreto -y dejando aparte un caso en que pellón hace referencia a un tipo de dulce-, se trata de 16 casos americanos y siete que, a pesar de mostrarse en CORDE como españoles, aparecen en textos de temática americana (Relación geográfica e histórica de la provincia de Misiones, D. de Alvear, 1790; Relación histórica del viaje a los reinos del Perú y Chile, H. Ruiz, 1793), circunstancia que es necesario tener en cuenta en estudios como los que se están llevando a cabo en estas páginas (Ramírez Luengo, en prensa b). Para una revisión de algunos de los problemas que CORDE presenta a este respecto, véase Ramírez Luengo (en prensa).

Para un estudio monográfico de estos elementos en el texto, véase Ramírez Luengo (en prensa c).

18 Aunque el DAMER (2010, s.v. hacienda) define este término como 'terreno de gran extensión dedicado a la agricultura y a la ganadería', su constante aparición en el texto junto a la referencia "de ganado bacuno, caballar, mular y lanar" (pp. $7,8,11$ ) demuestra que para su autor la hacienda solo presenta finalidad ganadera, en consonancia con el significado especializado del vocablo que se descubre en México (Morínigo, 1998, s.v. hacienda) o Costa Rica (Quesada Pacheco, 1995, s.v. hacienda); se trata, en todo caso, de un americanismo semántico muy temprano, como demuestra sobradamente Frago $(1999,57,88)$ con ejemplos del mismo siglo XVI. 
Por lo que toca a este término, cabe indicar que en la obra no presenta el valor canario y americano de 'hacienda de caña donde se fabrica azúcar' (Corrales Zumbado y Corbella, 2010: s.v. ingenio; Morínigo, 1998: s.v. ingenio), sino que se refiere más bien al significado actualmente boliviano y peruano de 'planta donde se procesa el mineral' (DAMER, 2010: s.v. ingenio; Morínigo, 1998: s.v. ingenio), según evidencia el siguiente ejemplo: "hay muchos ingenios de fierro, plomo, ocre, bol y yeso" (p. 11). Salta a la vista, por tanto, que es necesario ampliar la distribución histórica de esta acepción, que resulta frecuente en América en el siglo XVI (Corrales Zumbado y Corbella, 2010: s.v. ingenio) y que, a la luz de estos casos, parece conservarse en el siglo XIX en zonas como América Central.

Para un estudio complejo del deslizamiento semántico que lleva de una significación a la otra -así como para datos históricos sobre tal proceso-, véase DCECH (1980-91, s.v. licor).

21 Esto es, al menos, lo que parece poder extraerse del texto, donde los ladinos se contraponen a los indígenas sin que se haga ninguna referencia al idioma que emplean, en contraste, por ejemplo, con todas las apariciones de este término de los siglos XVIII y XIX presentes en CORDIAM; el significado centroamericano, con todo, no es novedad del Ochocientos, pues se puede descubrir en diversas áreas de la región ya desde los primeros años del siglo XVIII (Quesada Pacheco, 1995, s.v. ladino; Ramírez Luengo, 2010, 892).

22 En concreto, los datos numéricos -siempre sobre millón de palabras- son los siguientes: añil, 3'58 (Esp.)/12'03 (Am.); cacao, 4'87 (Esp.)/ 47'02 (Am.); canoa, 2'75 (Esp.)/46'86 (Am.); pita, 1'23 (Esp.)/6'25 (Am.).

23 Hecho que se puede retrotraer ya a los siglos XVIII y XIX y que confirman, una vez más, los datos de CORDE: 2'91 apariciones por millón de palabras en España y 32'66 en el caso de América.

24 Esta preferencia por la forma arcaizante en el Nuevo Mundo queda demostrada también con los datos que ofrece CORDIAM para las dos centurias ya mencionadas: 260 casos de esta y 98 de hierro, esto es, el 72'62\% de la primera frente a un escaso 27 '37 de la segunda.

25 Al menos eso parecen evidenciar las explicaciones que ofrece en el texto, sea en forma de doblete léxico ("frijoles o judías", p. 6) o sea por medio de una nota a pie de página en la que se indica que "frijol es lo mismo que judía en Europa" (p. 8).

26 Entre otros que será necesario estudiar con calma, cabe mencionar a manera de ejemplo el contacto más o menos temprano de los españoles con los pueblos indígenas de la región, la presencia más o menos abundante de estos, el mantenimiento más o menos continuado de ese contacto, la mayor o menor integración de los pueblos autóctonos en la sociedad criolla o el estatus más o menos prestigioso de las lenguas indígenas en la zona (Ramírez Luengo, en prensa).

27 Esto demuestra lo acertado de la afirmación de Frago (2010, 231) de que el empleo del indigenismo "no es cuestión, pues, de preferencias personales ni de condicionamientos ideológicos, sino de la pura y simple necesidad comunicativa".

28 En concreto, el DCECH (1980-91, s.v. achiote, batata, bejuco, cacao, canoa, hamaca, maíz, pita) los documenta en su totalidad ya en el mismo siglo XVI.

Por ello, quizá lo más interesante en este punto sea mencionar, por un lado, la alta frecuencia de voces antillanas, que resultan claramente predominantes; por otro, la escasez de elementos tomados del maya, algo que coincide con lo que diversos estudiosos han señalado, por ejemplo, para el español yucateco o guatemalteco de distintos momentos históricos (Polo Cano, 2005, 192; Ramírez Quintana, 2008, 1477; Quirós García y Ramírez Luengo, 2015, 199-200). Cabe mencionar, todavía en relación con los préstamos amerindios, la abundantísima presencia de topónimos tomados de las lenguas regionales -a manera de ejemplo, Totonicapán, Chimaltenango, Sacatepéquez, Escuintla, Suchitepéquez o Quezaltenango (p. 4)-, cuestión que sin duda merece un estudio específico que no cabe en estas páginas. 
El empleo de esta voz en la Centroamérica decimonónica queda demostrado por su atestiguación en Costa Rica en 1834 (Quesada Pacheco, 1995, s.v. guate); falta, con todo, explicar la derivación guatazón y el valor preciso del vocablo, así como su ámbito diatópico de uso en el Ochocientos.

31 En concreto, CORDE ofrece catorce apariciones en diversos países americanos (Argentina, Chile, Cuba, Ecuador, México, Venezuela, etc.) durante las dos centurias mencionadas, mientras que los datos de CORDIAM y LEXHISP se reducen respectivamente a un ejemplo en Guatemala y dos en Cuba y Colombia; cabe mencionar, además, que dos de las atestiguaciones venezolanas aparecen en textos donde se menciona a los españoles, lo que parece favorecer la idea de que su empleo en tales casos se produce por asociación con este país.

Cabe todavía una explicación adicional, y es que la larga estancia de Méndez en España -seis años para cuando publica su obra- haya producido en su idiolecto el cambio léxico papa > patata como resultado de los procesos de nivelación dialectal mencionada en la nota 4; tales modificaciones en el vocabulario, como es sabido, no resultan extrañas en situaciones de contacto intralingüístico (Ramírez Luengo, 2014).

\section{REFERENCIAS BIBLIOGRÁFICAS}

ÁLVAREZ DE MIRANDA, P. 1992. Palabras e ideas: el léxico de la Ilustración temprana en España (1680-1760). Madrid: Real Academia Española.

ÁLVAREZ DE MIRANDA, P. 2009. "Neología y pérdida léxica", en Miguel, E. de (ed.), Panorama de la lexicología. Barcelona: Ariel, 133-58.

BELAUBRE, C. 2015. "Méndez, José Mariano". Asociación para el Fomento de los Estudios Históricos en Centroamérica (AFEHC). Disponible en: http://www.afehc-historiacentroamericana.org/index.php?action=fi_aff\&oldid=136\&module=diccionario.

BUESA, T. y ENGUITA, J. M. 1992. Léxico del español de América. Su elemento patrimonial e indígena. Madrid: MAPFRE.

COMPANY, C. 2007. El siglo XVIII y la identidad lingüística de México. México DF: Universidad Nacional Autónoma de México - Academia Mexicana de la Lengua.

COMPANY, C. 2010. "Introducción", en Diccionario de Mexicanismos, Academia Mexicana de la Lengua. México DF: Siglo XXI, xv-xxiii.

CORDE. REAL ACADEMIA ESPAÑOLA. 2016. Banco de datos CORDE. Corpus diacrónico del español. Disponible en: http://corpus.rae.es/cordenet.html.

CORDIAM. ACADEMIA MEXICANA DE LA LENGUA/ACADEMIA NACIONAL DE LETRAS DEL URUGUAY. 2016. Corpus Diacrónico y Diatópico del Español de América. Disponible en: http://www.cordiam.org/.

CORRALES ZUMBADO, C. y CORBELLA, D. 2010. Tesoro léxico canario-americano. Las Palmas de Gran Canaria: Cabildo de Gran Canaria - Casa de Colón.

DAMER. ASOCIACIÓN DE ACADEMIAS DE LA LENGUA ESPAÑOLA. 2010. Diccionario de Americanismos. Madrid: Santillana.

DCECH. COROMINAS, J. y PASCUAL J. A. 1980-1991. Diccionario crítico etimológico castellano e hispánico. Madrid: Gredos.

DMEX. ACADEMIA MEXICANA DE LA LENGUA. 2010. Diccionario de Mexicanismos. México DF: Siglo XXI.

DOMÍNGUEZ, R. J. 1853. Suplemento al Diccionario Nacional o Gran Diccionario Clásico de la Lengua Española. Madrid/París: Establecimiento de Mellado.

DRAE. REAL ACADEMIA ESPAÑOLA. 2014. Diccionario de la Lengua Española. Madrid: Espasa-Calpe. 
FRAGO, J. A. 1999. Historia del español de América. Madrid: Gredos.

FRAGO, J. A. 2010. El español de América en la Independencia. Santiago de Chile: Taurus.

GARCÍA GODOY, M. T. 1999. El léxico del primer constitucionalismo español y mejicano (1810-1815). Granada: Universidad de Granada.

GRANDA, G. DE. 1994. "Un septentrionalismo semántico peninsular en el español paraguayo: valle "comarca rural”", Estudios Filológicos, 29, 25-32.

HERNÁNDEZ, E. 2008. "Indigenismos en el Vocabulario de la lengua cakchiquel atribuido a fray Domingo de Vico, ms. BNF R. 7507”, Revista de Filología Española, 88(1), 67-88.

HILDEBRANT, M. 1961. La lengua de Bolívar, I. Léxico. Caracas: Universidad Central de Venezuela.

JUARROS, D. 1810. Compendio de la historia de la Ciudad de Guatemala, II. Guatemala: Ignacio Beteta.

LEXHISP. BOYD-BOWMAN, P. 2003. Léxico hispanoamericano. 1493-1993. Nueva York: Hispanic Seminary of Medieval Studies. Disponible en: http://textred.spanport.lss.wisc.edu.

MEDINA LÓPEZ, J. 1995. El español de América y Canarias desde una perspectiva histórica. Madrid: Verbum.

MEJÍAS, H. A. 1980. Préstamos de las lenguas indígenas en el español americano del siglo XVII. México DF: Universidad Nacional Autónoma de México.

MORÍNIGO, M. A. 1998. Nuevo Diccionario de Americanismos e Indigenismos. Buenos Aires: Claridad.

NIETO, M. E. 1995. El español de Honduras en el periodo colonial. Tegucigalpa: Universidad Nacional Autónoma de Honduras.

PENNY, R. 2004. Variación y cambio en español. Madrid: Gredos.

PÉREZ BRIGNOLI, H. 2000. Breve historia de Centroamérica. Madrid: Alianza.

PÉREZ CORDÓN, C. y RAMÍREZ LUENGO, J. L. 2007. "El español de Guatemala en el siglo XVIII: un memorial de un criollo”, en Pérez Cordón, C. y Ramírez Luengo, J. L. (eds.), El español en sus textos. Manual de comentarios lingüísticos y filológicos. Lugo: Axac, 99-108.

POLO CANO, N. 2005. "Algunos indigenismos léxicos en el español de Guatemala del siglo XVIII”, Res Diachronicae Virtual, 4, 185-202.

QUESADA PACHECO, M. A. 1995. Diccionario histórico del español de Costa Rica. San José: Editorial Universidad Estatal a Distancia.

QUESADA PACHECO, M. A. 1987. "El español de Juan Vázquez de Coronado. Análisis descriptivo de un idiolecto de principios de la colonia”, Revista de Filología y Lingüústica de la Universidad de Costa Rica, 13(1), 167-182.

QUESADA PACHECO, M. A. 1996. “El español de América Central”, en Alvar, M. (dir.), Manual de Dialectología Hispánica, II. El español de América. Barcelona: Ariel, 101-115.

QUESADA PACHECO, M. A. 2009. Historia de la lengua española en Costa Rica. San José: Universidad de Costa Rica.

QUESADA PACHECO, M. A. 2013. "El sistema verbal del español de Costa Rica en los albores de la época independiente”, Signo y Seña, 23, 81-102.

QUIRÓS GARCÍA, M. y RAMÍREZ LUENGO, J. L. 2015. "Observaciones sobre el léxico del español del Yucatán (1650-180o)”, Revista de Filología Española, 95(1), 153-181.

RAMÍREZ LUENGO, J. L. 2003. "Las segundas personas en el español guatemalteco del siglo XVIII", Res Diachronicae. Anuario de la Asociación de Jóvenes investigadores de Historiografía e Historia de la Lengua Española, 2, 266-274.

RAMÍREZ LUENGO, J. L. 2004-2005. "Contribución a la historia del español de Honduras: edición y estudio de documentos hondureños del siglo XVIII", Anuario de Letras, 42-43, $51-75$. 
RAMÍREZ LUENGO, J. L. 2006. "Aproximación al español de Guatemala en el siglo XVIII: algunas características fonético-fonológicas”, Lexis, 30(2), 259-72.

RAMÍREZ LUENGO, J. L. 2007. Breve historia del español de América. Madrid: Arco/Libros.

RAMÍREZ LUENGO, J. L. 2008. "El futuro de subjuntivo en el español centroamericano del siglo XVIII: vitalidad, empleo e indicios de decadencia”, Nueva Revista de Filología Hispánica, 56(1), 141-154.

RAMÍREZ LUENGO, J. L. 2010. "Notas sobre el español salvadoreño del siglo XVIII”, en Encinas, M. T. et al. (comps.), Ars Longa. Diez años de AJIHLE, II. Buenos Aires: Voces del Sur, 879-896.

RAMÍREZ LUENGO, J. L. 2011. La lengua que hablaban los próceres. El español de América en la época de las Independencias. Buenos Aires: Voces del Sur.

RAMÍREZ LUENGO, J. L. 2012. "Una aportación a la historia de la lengua española en Nicaragua: algunos datos sobre el siglo XVIII”, en García Godoy, M. T. (ed.), El español del siglo XVIII. Berna/Bruselas/Nueva York: Peter Lang, 293-312.

RAMÍREZ LUENGO, J. L. 2014. "Contacto interdialectal en la historia del léxico: los americanismos en la Relación de Aller (Móxos, Bolivia; 1668)”, en Santos Rovira, J. M. (ed.), Fronteras y diálogos. El español y otras lenguas. Lugo: Axac, 165-176.

RAMÍREZ LUENGO, J. L. 2015. "El americanismo y la historia: algunas pautas diacrónicas de creación de americanismos (léxicos)”, Miradas, 13, 114-123.

RAMÍREZ LUENGO, J. L. (en prensa). "Aspectos metodológicos para el estudio histórico del léxico americano: conceptos, ejemplificación y tareas para el futuro”, Moenia, 23, 2017.

RAMÍREZ LUENGO, J. L. (en prensa b). "Los corpus lingüísticos en la historia del léxico: algunos datos sobre la generalización de los indigenismos antillanos en el español de España”, Études Romanes de Brno.

RAMÍREZ LUENGO, J. L. (en prensa c). "Contribución a la historia léxica del español de América Central: algunos americanismos semánticos de la primera mitad del siglo XIX”, en Carpi, E. (ed.), El español del siglo XIX: herencia e innovación. Pisa: Universidad de Pisa.

RAMÍREZ QUINTANA, P. A. 2008. "Caracterizadores léxicos del español colonial en Campeche: la lengua maya”, en Company, C. y Moreno de Alba, J. G. (eds.), Actas del VII Congreso Internacional de Historia de la Lengua Española, II. Madrid: Arco/Libros, 1471-1483.

REAL ACADEMIA ESPAÑOLA. 1979. Diccionario de Autoridades (edición facsímil de la edición de 1726-1739). Madrid: Gredos.

RICHARD, R. 1997. Diccionario de Hispanoamericanismos. Madrid: Cátedra.

SANTAMARÍA, F. J. 1959. Diccionario de mejicanismos. México DF: Porrúa.

TARACENA ARRIOLA, A. 1985. "El voseo en la literatura guatemalteca en el siglo XIX”, Anales de la Academia de Geografía e Historia, 59, 29-35.

ULATE ZÚÑIGA, R. 1991. El seseo en el español escrito en el noroeste de Costa Rica durante el siglo XVI. Zonas de Esparza y Guanacaste. Tesis de licenciatura inédita. San José: Universidad de Costa Rica.

\section{NOTA SOBRE EL AUTOR}

José Luis Ramírez Luengo es doctor en Filología Hispánica y profesor de la Universidad Autónoma de Querétaro, México. 